\title{
LAW AND ETHICS
}

\section{Clinical issues on consent: some philosophical concerns}

\section{R Worthington}

J Med Ethics 2002;28:377-380

Correspondence to: Dr R Worthington, Medicines Policy Unit, Department of Pharmacology \& Clinical Pharmacology, St George's Hospital Medical School, London SW17 ORE, UK; rworthin@sghms.ac.uk

Revised version received 24 June 2002 Accepted for publication 28 June 2002

\begin{abstract}
On occasions, laws on consent are subject to modification, largely on account of being subject to common law rather than statute - for example, in the UK. Guideline publications such as the UK Department of Health Reference Guide to Consent for Examination or Treatment are intended to provide information for clinicians on when and how to apply current laws in everyday clinical situations. While the extent to which guidelines influence clinician behaviour depends on how much they are read and followed, what is also relevant, and sometimes omitted from consideration, is discussion about underlying philosophical concepts.

This paper analyses philosophical weaknesses relating to English laws on consent, the main focus of attention being applied ethics and the rights of adults with incapacity. It draws comparisons between the US and the UK, and advocates changes in English law in order to help rectify weaknesses in patient protection. Discussion includes references to Scottish law, and the use of advance directives, and it voices concerns about over-reliance on "best interests" determinations. The problem is partly one of logical analysis, and what can happen is that best interests determinations fail to show proper respect for adults lacking the capacity to consent to examination or treatment on their own behalf. This is fundamentally a matter of rights, and requires further investigation and appropriate legal remedies in order to respond to ethical deficiencies in English law as it now stands.
\end{abstract}

$\mathrm{T}$ he focus of this paper is on clinical or applied ethics, dealing with specific issues relating to consent. Since the boundary between personal and professional autonomy is shifting, as too is the legal position as regards rights (postimplementation in 2000 of the Human Rights Act 1998), it seems a good time to reappraise important issues arising in the context of clinical ethics and consent. In some measure the issues impact on all patients and clinicians, and it is my view that philosophical concerns can be crowded out by "lawyerly" type concerns; this paper is in part an attempt to try and redress the balance. Part one focuses on issues relating to information, professionalism, and rights, and part two concentrates on decision making for non-competent adults.

\section{I}

The main purpose behind the requirement to seek valid consent from patients before an intervention is to uphold and reinforce the concept of patient autonomy. Informed consent empowers patients and allows them to take part in critical decision making, as long as they agree to play an active part and have the capacity to do so. As part of the process patients must have the opportunity to say "no" and to be presented with alternative courses of action where they exist. Respecting patient autonomy is fully consistent with the trend towards showing greater respect for patient rights in the general context of health care service provision. This trend is well established in the US, but it is still quite "young" in the UK, and the rights based element is fundamental to the underlying philosophical concept, which affects the practising professional just as much it does as the patient.

It has rightly been said that "the validity of consent does not depend on the form in which it was given", ${ }^{1}$ and in the UK oral consent is regarded as sufficient for most interventions. If matters at hand involve serious risk or if there are complicating factors then written consent is advisable, and although written consent provides a better record of proceedings, clinicians can slip into the habit of asking patients to sign a piece of paper without any thought being given to either what is on the form or to its primary purpose. The ethical validity of consent hinges not on the written word, but on the nature and quality of the interaction between patient and clinician. Signatures and record keeping are just one part of the process, and because informed consent should be about moral rights and respect for persons not avoidance of suit, then from an ethical point of view, the written versus oral argument does not give cause for concern.

A recent UK Department of Health publication Reference Guide to Consent for Examination or Treatment (2001) states that it is: "a fundamental part of good practice" for patients to be able to help determine "what happens to their own bodies", and this basic assertion should not be open to dispute. ${ }^{2}$ What is less clear is the extent to which the government and/or the professions assume responsibility for defining ethical standards of consent. For many years, there have been only minor modifications in English laws on consent, triggered by cases such as Bolitho and Pearce, ${ }^{3}$ and in the absence of any statutory provision, the law does not give an especially clear lead in terms of defining the limits of obligation and responsibility. It is perhaps within the medical profession that greater changes are going to be found, and it could be argued that there has never been a time of such fundamental reappraisal of the role of the medical professions. ${ }^{4}$ If this represents a shift away from a paternalistic model of health care delivery, then it should be welcomed; however, if, as a result of public and political pressure, professional autonomy and patient autonomy have come into conflict then that is not so helpful.

I agree with Brazier and Miola when they say that fortunately "the day of the unfettered autonomy of the individual consultant is over", ${ }^{5}$ but because of increasing pressure towards accountability in the provision of health care services clinicians can sometimes feel under siege. ${ }^{6}$ I refrain from discussing the political implications of this situation and will consider instead the question of defining standards. The question of standards is linked to the amount of disclosure required from clinicians in order to properly inform their patients. English case law states that doctors should always inform the patient of a "significant risk which would affect the judgment of a reasonable patient". ${ }^{7}$ But this represents a clarification rather than a departure from the Sidaway standard of disclosure, ${ }^{8}$ and that judgment in 1985 effectively reinforced the Bolam test, whereby a patient only had to be told 
what a reasonable body of professional opinion would consider appropriate (in terms of information about risks). ${ }^{9}$

Since 1998 the UK General Medical Council (GMC) has been advising that "doctors should do their best to find out about patients' individual needs and priorities when providing information about treatment options" ${ }^{10}$ This standard is slightly more demanding than the one outlined by the Department of Health. The reference guide states that in order "to give valid consent the patient [only] needs to understand in broad terms the nature and purpose of the procedure". ${ }^{11}$ This latter recommendation lays out the minimum standard required to satisfy legal criteria and avoid culpability, but ethically speaking, the question of standards has not been made transparently clear, and there is still room for debate.

In the general context of clinical ethics health care professionals need to be aware that a) failure to follow the recommended protocols for obtaining meaningful, lawful consent is unethical and can harm patients both physically and psychologically; b) failure to obtain consent can end in either civil litigation or in rare cases, criminal prosecution, and c) quality health care demands more than mere technical proficiency, and wherever possible it needs to allow for active patient participation. This cannot be achieved in an atmosphere of mistrust, or if patients feel that what they think and say is of no real consequence. Lingering paternalism is not part of good practice, and cannot be excused by being disguised as mere beneficent intent (or "doctor knows best"). Granted, beneficence is not the same as paternalism, but it is easy to slide from one to the other in the absence of some form of moral grounding or framework in support of ethical standards of professionalism.

For consent to be valid the patient must be properly informed about risks and benefits, which requires a two way transfer of information in a meaningful and accessible form. Such a transfer has to ensure that there is understanding on the part of patients about key issues affecting their care, and without a reasonable level of comprehension the exercise of seeking consent loses its moral significance. The "information exchange" therefore forms a central part of the decision making process, especially when there are serious issues at stake, and practical benefits may be gained from good communication, such as those relating to patient wellbeing. ${ }^{12}{ }^{13}$

The power of knowledge is no longer vested just in the hands of the few-that is, the medical "expert", and patients are probably better informed now than in the past; however, information and comprehension are not the same thing. Comprehension on the part of patients is most likely to occur where good clinical practice is observed, which is a matter of professionalism as much (or more) than it is about mere compliance with the law. Information that is not assimilated or viewed from within an appropriate framework may be of limited value, and effort has to be worth expending in terms of sharing available information in the most effective way. To conclude otherwise is to undermine the whole basis upon which informed consent is built.

Clinicians critical of the doctrine of informed consent (or informed choice, which is a more meaningful expression) might argue that there is not enough time to spend talking about personal values and patient preferences when there are lives to be saved and operations to be performed. Clinicians can also argue that valuable clinical time should not be spent discussing things which patients do not need to know and are unlikely to understand. These arguments may have some validity, but they should not be used as an excuse for failing to involve patients in their care. Time constraints are an everyday reality in the business of providing patient care, and what may be advisable is a sensible policy on delegating all or part of the process of seeking patients' consent (provided the person appointed to the task has the appropriate knowledge). ${ }^{14}$ Affording the luxury of extensive consultations with senior staff would be counterproductive if ultimately it resulted in denial of care or unnecessary delays for other patients further down the line.

Clinicians who are themselves seeking information about the underlying principles of consent, but do not want to search through unfamiliar bodies of literature, need to be able to access relevant supporting information. This could be provided in several ways, such as through guideline publications, or, perhaps more effectively, by the provision of training opportunities in law and ethics as a regular feature of continuing medical education.

In terms of undergraduate medical education, students, who in the UK should now receive basic training on law and ethics under the heading of personal and professional development, ought to be familiar with the major issues relating to consent. This understanding is likely to affect future conduct since students acquire habits during the course of training that can follow them throughout their careers. The idea of the role model is therefore particularly important when it comes to demonstrating ethical standards, imposing a special type of burden on the clinician-teacher. It is sometimes felt, however, that a gap exists between classroom teaching and actual clinician conduct. ${ }^{15}$ Unless practising clinicians routinely demonstrate respect for patient rights, including the principle of informed consent, it may be hard for young doctors to carve their own way forward when it comes to determining standards of appropriate conduct. There will always be variations in clinicians' knowledge of the law, which in the postBristol era is perhaps significant, ${ }^{16}$ but I argue that it is also important to address philosophical issues intrinsic to broader concerns relating to autonomy and consent.

Clinicians can be dismissive of guidelines perceived as calling into question the value of clinical judgment, the inference being that guidelines inhibit freedom to act and restrict professional autonomy. But they do help to define common standards, and clinicians mindful of their responsibility to bring patients into the decision making process may find the Reference Guide to Consent for Examination or Treatment a useful source of information. The publication refrains from entering into any form of ethical debate, which in a sense is disappointing, but it may not be the responsibility of central government to do anything other than provide legal explanations in guideline publications. If that is the case, then it is not helpful if a legal exposition is the only source of information readily available to the clinician, suggesting the need for a more balanced presentation of philosophical and legal perspectives.

II

The difference between what is legal and what is moral is as intriguing as it is contentious, and Hoffman LJ's assertion in the Bland ruling (1993) that "I would expect medical ethics to be formed by the law rather than the reverse $\mathrm{e}^{\prime 17}$ ought not to go unchallenged. I endorse the view that the law reflects ethical and moral standards rather than determines what they should be, but while I accept that there are theorists who endorse a different point of view, whereby the law is said to fulfil a more socially proscriptive role, ${ }^{18}$ such a position does not leave enough room for philosophical debate. In terms of ethics, it is a question of whether to start with the law and work down in order to define ethical conduct (deciding each case according to established principles), or begin with a philosophical debate about social values and fashion the law accordingly (framing each decision according to the circumstances surrounding that particular case). I favour the latter approach, and in that both the law and social values evolve over time it matters if, when, and how each responds to changes in the other. (For discussion on these issues see Legal theory, Cambridge University Press and the Oxford Journal of Legal Studies, Oxford University Press.) 
In terms of consent, I have two particular philosophical worries, albeit arising as points of law. Firstly, the expression "best interests" enjoys a measure of legal status that I believe is disproportionate to its usefulness. Whilst a patient's best interests are not necessarily confined to best medical interests ${ }^{19}$ the reasoning that allows a clinician to act and make a determination on behalf of a patient with incapacity is not without difficulty. This is significant, given that under English law no one other than the patient can give consent to examination or treatment. Since this makes clinicians primary decision makers for non-competent patients, questions arise about how to assess whether a proposed intervention really is in a patient's best interests.

The Reference Guide to Consent for Examination or Treatment advises that while:

\section{Parents, relatives or members of the health care team can not consent on behalf of such an [incompetent] adult . . . it is good practice for the health care team to involve those close to the patient in order to find out about the patient's values and preferences before loss of capacity, unless the patient has previously made clear that particu- lar individuals should not be involved. ${ }^{19}$}

Indeed, but the health care team may have no means of determining what the values system and preferences of a patient might be other than to stay alive. But even that is making an assumption, and in exceptional cases respecting patient autonomy can result in lawful death. ${ }^{20}$ Among various difficulties, there may be no one close to the patient with whom to consult at the time of a medical emergency; friends and family (if present) may not agree on what is best for the patient; also, it is quite likely that patients may have never talked about the circumstances pertaining to their present situation.

It is not the fact that decisions may have to be made in less than ideal circumstances that is at issue; what really counts is the ethical process of how such decisions are made. While decisions can be made by reference to prevailing medical opinion - that is, by applying the Bolam test-the validity of this measure is not at all beyond dispute. ${ }^{21}$ Furthermore, where medical necessity is the main criterion of relevance it can result in substituted judgment, whereby clinicians are left to decide according to their own values what may or may not be in a patient's best interests. Such a decision can easily be made on the basis of what a clinician would most likely want to happen to him or her, given similar circumstances, and often as not, this is the best that can be done under conditions of pressure.

The issue is not what is meant by medical necessity (and so provide justification for a proposed intervention), but how decisions are made on a case by case basis, and I argue that as a concept "best interests" is too ill defined for it to be considered meaningful, hence for it to have ethical validity. Deferring to "best interests" has a tendency towards circularity, and logical analysis simply does not permit one thing to be defined by reference to something no more defined than itself. If "best interests" is such a nebulous concept, why is so much reliance placed on it in terms of clinical practice and the law?

On a positive note, it is encouraging to find a whole section on the new Department of Health consent form (for use with non-competent patients) devoted to input from the patient's family and others close to the patient..$^{22}$ This is a step in the right direction, but it must be remembered that a) this form is anachronistic because it only serves as a written record of the process of consultation and is not a consent form at all, and b) it is too soon to be able to evaluate usage of these forms - that is, whether they are being widely used, whether clinicians know which of the four forms to complete in which case, or how well the new forms have been received by patient groups.
The courts, if called upon, have powers to intervene and make a determination that a judge considers lawful and in the patient's best interests. But this does not circumvent the philosophical problem-it simply relocates the process of determination farther away from the patient-that is, from the hospital to the courtroom. Mason and McCall Smith are quite correct in saying that the concept of best interests is "vague and leaves considerable control and power in the hands of the health care professionals. Neither the precise nor the general nature of best interests is defined by the UK courts", ${ }^{23}$ and I argue that resorting to best interests determinations can add to patients' vulnerability and shows little respect for them as persons.

This awkward situation is not a reflection on the ability of a clinician to exercise clinical judgment, any more than it implies criticism of legal process. What it does mean is that too much reliance should not be placed on subjective interpretations of the facts of any particular case, and that it is ethically impossible to determine a proper course of action by reference to a concept that is essentially so vague. The implication of this finding is that the rights of non-competent patients may be seriously impaired. Lack of capacity cannot often be predicted, and such a state is normally completely unavoidable. It is one thing, however, to lose one's autonomy as a result of accident or illness, and it is something else to suffer loss of respect, given that whatever the level of capacity, a patient is always a person, hence deserving of the fullest respect.

This leads me on to the second point, namely consenting on behalf of another.

In the United States the idea of using an advanced directive is well established. While states' laws largely govern the use of advanced directives, the matter has been the subject of federal legislation, and The Patient Self Determination Act 1990 followed on the heels of certain well publicised cases. ${ }^{24}$ Currently, a New York state health proxy form-for example, can be downloaded off the internet, completed, and distributed to potentially interested parties such as one's attorney, health care provider, and next of kin, as well as the individu$\mathrm{al}(\mathrm{s})$ named on the form. ${ }^{25}$ This is simple, but only effective if everyone knows that you have appointed one or more health proxies and that they can physically be contacted when needed. It is not the same as enduring power of attorney and applies only to medical decisions, but it has the key advantage of empowering someone to give consent to treatment or examination on behalf of incapacitated patients, thus showing greater respect for them as persons.

Health proxies potentially make the work of the clinician easier (if patients remember to carry a card with the name and telephone number of their proxy), provided that an attitude of confrontation can be avoided between the proxy and the clinician. The proxy should be informed about the previously expressed wishes of the patient and be able to communicate effectively with members of the health care team, but these possible limitations need not present a serious obstacle. Such a system may not be perfect, but it shows due respect for patient autonomy in deciding on a course of action when a patient has lost capacity.

The other type of advance statement (normally drawn up at the same time as appointing a health care proxy) is the so-called living will. This document allows patients to express in their own words what they would or would not like done in the event of illness or incapacity. It needs to be notarisedthat is, signed by a notary public and centrally deposited, so that if one is away from home, family and/or regular health care provider a) it is known that you have made such a will, and b) that the clinician can gain access and find out what it contains-perhaps something as pivotal as a DNAR order (do not attempt resuscitation). This device is thus respectful of the principle of autonomy, and while the topic of advance directives has recently been discussed in the British medical press, ${ }^{26-28}$ it merits receiving further attention by virtue of 
necessity, in that the law itself is so inadequate. It is unfortunate that an Adults with Incapacity Bill for England remains in draft form and has yet to be brought before parliament. ${ }^{29}$

These models for advance directives work with reasonable efficiency in the US, but would need adaptation before they could be effectively introduced in the UK, on account of legal, social, and organisational differences. From an ethical standpoint, however, they offer an appropriate way of respecting the rights and wishes of the non-competent adult patient, as has now received recognition in Scotland..$^{30}$ One potential pitfall is that patients (when they become patients) do not always behave in the way that they themselves anticipated when perfectly healthy and giving thought to these matters in the abstract. It is one thing being cool, calm, and collected and talking things over with one's family or partner-it is another thing finding oneself victim to a serious accident or illness and fighting for one's life or to preserve some sense of dignity. No amount of preparedness can put one in a frame of mind that can mirror such an eventuality; however, this does not justify abandoning the whole exercise of making advance directives. Rather it provides an indication that such matters are complex and need regular and careful deliberation.

A further idea widely used in the US is that of the ethics consult, whereby a team of experts, including close family members, health care proxies (if appointed), the physician in charge, other members of the medical team, plus a clinical ethicist, and one or more lawyers meet to discuss a case. This should result in a clear recommendation being made regarding a particular patient, and it is common for large general hospitals to have a resident clinical ethicist, who can be called upon as required. Ethically speaking, the consultation idea has much to commend it, and it can serve as a means of protecting patients' interests, and help defuse situations in which there is disagreement between the parties involved.

Granted, it would place an extra burden on the National Health Service (NHS) to try and organise on the spot meetings, which can take place at very unsociable hours, but I believe the idea does merit consideration. If combined with the introduction of health proxies (or welfare attorneys, to use the Scottish term) such changes could significantly alter the decision making process for incapacitated adults, tipping the scales in the direction of patient rights. Clinicians need have no fear of a further erosion of their powers, as I believe it would enhance their profile with the patient's family, being seen to be actively engaged in the process, thus promoting transparency in the whole decision making process.

To conclude, it is my suggestion that legal theory more than legal practice can and should be drawn upon to enlighten the debate, by engaging in conceptual analysis that embraces core social and ethical values. But I make no suggestion that there is an easy set of answers just waiting in the wings, and space does not permit discussion here about questions of jurisprudence. It will require hard work, tenacity, and the combined input of clinicians, lawyers, ethicists, and politicians to try and resolve these highly complex problems. Meantime, the medical practitioner should not be left with the impression that a basic knowledge of health law is (ethically speaking) to state the whole case. I believe that more than anything else, the moral difficulty of making a judgment on behalf of another human being demands further critical attention, preferably in the not too distant future.

\section{ACKNOWLEDGEMENTS}

Opinions expressed are those of the author, not the institution, and I accept full responsibility for any errors. I am indebted, however, to Joe Collier (Professor of Medicines Policy), and Deborah Bowman (Lecturer in Medical Law and Ethics, both at St George's Hospital Medical School, London) for their helpful advice and valuable comments on earlier drafts of this paper.

\section{REFERENCES}

1 Department of Health. Reference guide to consent for examination or treatment . London: Department of Health, 2001. Available online: www.doh.gov.uk/consent

2 See reference 1: 2

3 Bolitho v Hackney Health Authority 4 [1997] All ER 771; Pearce v United Bristol Healthcare NHS Trust (1999) 48 BMLR 118.

4 Gray DP. Deprofessionalising doctors? British Medical Journal 2002;324:627-8

5 Brazier M, Miola J. Bye-bye Bolam: a medical litigation revolution? Medical Law Review 2000;8:85-114.

6 White C. Doctors under fire. British Medical Journal 2002;324:55.

7 See Reference 3: Pearce.

8 Sidaway v Royal Bethlem Hospital [1985 All ER 643, (HL).

9 Bolam v Friern HMC [1957] All ER 118.

10 General Medical Council. Seeking patients' consent: the ethical considerations. London: General Medical Council, 1998.

11 See reference 1:5

12 Brody H. The healer's power. New Haven, Connecticut: Yale University Press, 1992.

13 Wear S. Informed consent: patient autonomy and clinician beneficence within health care. Georgetown: Georgetown University Press, 1998.

14 See reference 1: 7-8.

15 Doyal L. Closing the gap between professional teaching and practice. British Medical Journal 2001;322:685.

16 Bristol Royal Infirmary Inquiry. Learning from Bristol: the report of the public inquiry into children's heart surgery at the Bristol Royal Infirmary 1984-1995. (Cmnd 5207.) July 2001. http:// www.bristol-inquiry.org.uk/index.htm

17 Airedale NHS Trust v Bland [1993] AC 789 at 834

18 See-for example, Raz J. Authority. New York: New York University Press, 1990.

19 See reference 1: 12

$20 \operatorname{Re} C$ [1993] All ER 819

21 See reference 5 .

22 Form number 4: http://www.doh.gov.uk/consent/ abouttheconsentform.htm (New consent forms posted on the internet, 2001 November.

23 Mason JK, McCall Smith RA. Law and Medical Ethics. London: Butterworths, 1999: ch 10: 264.

24 In particular, Cruzan v Director, Missouri Dept of Health $110 \mathrm{~S} \mathrm{Ct}$ 2841, 1990.

25 For information and specimen forms see: http://www.ama-assn.org/public/booklets/livgwill.htm

26 Gadd E. Changing the law on decision making for mentally incapacitated adults. British Medical Journal 1998; 316:90.

27 Diggory P, Judd M. Advanced directives: questionnaire survey of NHS trusts. British Medical Journal 2000; 320:24-5.

28 Ebrahim S. Do not resuscitate decisions: flogging dead horses or a dignified death? British Medical Journal 2000;320:1155-6.

29 This bill was the result of a Law Commission report. Law Commission. Report no 231: Mental incapacity (HC 189). London: The Stationery Office, 1995.

30 Adults with Incapacity (Scotland) Act 2000. http:/ www.scotland-legislation.hmso.gov.uk/legislation/scotland/s-acts.htm 